\title{
PEMFC Cathode Catalyst Contamination Evaluation with a RRDE-Methyl Methacrylate
}

Junjie Ge*, Jean St-Pierre, Yunfeng Zhai

Hawaii Natural Energy Institute, University of Hawaii- Manoa, 1680 East-West Road, POST 109, Honolulu, HI 96822, USA

Email address:

Junjie Ge: gejunjie@ @awaii.edu; gejjyht@gmail.com

Jean St-Pierre: jsp7@ @hawaii.edu

Yunfeng Zhai: yunfeng@ hawaii.edu

Corresponding author:

Junjie Ge, Email: gejunjie@ hawaii.edu; gejiyht@gmail.com

Tel.: +1 808593 1714; Fax: +1 8085931719 .

Address: Hawaii Natural Energy Institute, University of Hawaii- Manoa, 1680 East-West

Road, POST 109, Honolulu, HI 96822, USA 


\section{Abstract}

This study was undertaken to provide insight into the mechanism of methyl methacrylate (MMA) contamination on the cathodes in proton exchange membrane fuel cells (PEMFCs). The effect of various concentrations of MMA on the oxygen reduction reaction (ORR) was investigated using a rotating ring-disk electrode (RRDE). The adsorption of MMA on the Pt/C electrode leads to a reduction in the electrochemical surface area (ECSA) and a decrease in the mass activity of the ORR. Increasing the MMA concentration causes an increase in its coverage on Pt and a decrease in the ORR mass activity. At high MMA concentration $(0.1 \mathrm{M})$, the $\mathrm{O}_{2}$ transportation is also affected, resulting in a large decrease in the diffusion limiting current. For all of the MMA concentrations measured, a shift in the ORR reaction pathway from a 4-electron to 2electron mechanism is observed, as indicated by the increase in the $\mathrm{H}_{2} \mathrm{O}_{2}$ production on the ring. Using the RRDE measurements and the Levich plots, the total charge transfer number is confirmed to decrease from 4 for the clean electrode to lower values due to the increase in the $\mathrm{H}_{2} \mathrm{O}_{2}$ side reactions. The shift in the reaction pathway is hypothesized to be caused by the inhibition of dual adsorption of the $\mathrm{O}_{2}$ molecules, due to steric hindrance induced by MMA adsorption on the Pt/C electrode. Tafel evaluation indicates a continuous increase in the slope with an increase in the MMA concentration, which indicates that the passage of electrons for the ORR at the electrode surface is altered by the adsorption of MMA. A recovery effect was also investigated and a water rinsing process was used to recover the electrode. Only a partial recovery was obtained with a water rinse followed by potential cycling over the same potential range as the initial 
ECSA measurements. The unrecovered performance is attributed to MMA remnants on the catalyst surface, which can be removed by potential cycling over a wider potential range with a larger anodic potential limit.

Keywords: Methyl Methacrylate; ORR; RRDE; Airborne Contaminant; PEMFC

\section{Introduction}

Proton exchange membrane fuel cells (PEMFC) are considered a promising clean energy technology and are being developed as a power system alternative for many applications. The commercialization of PEMFCs faces several challenges, such as slow oxygen reduction reaction (ORR) kinetics and limited cell durability due to several degradation mechanisms [1]. PEMFCs are particularly susceptible to performance degradation by airborne contaminants because the system is open to the ambient atmosphere $[2,3]$. As the cathode material, the $\mathrm{Pt} / \mathrm{C}$ catalyst is highly active and readily adsorbs/reacts with a large range of inorganic and organic species. Therefore, the cathode performance of PEMFCs is expected to be influenced by undesirable contaminants due to the sluggish ORR kinetics and the Pt affinity to the impurities. In the literature, most of the contamination studies were focused on inorganic species, such as $\mathrm{SO}_{2}, \mathrm{NO}_{2}, \mathrm{NH}_{3}$ and $\mathrm{Cl}^{-}$, and different deleterious effects with varied contamination mechanisms were confirmed for the PEMFC performance [1, 4-8]. The organic contaminants, which potentially have more significant performance effects, have been ignored to a large extent $[9,10]$. Because many organic molecules have the potential to contaminate PEMFC, a large amount of work is expected to be performed for contamination evaluation and 
mitigation strategy development. To provide useful contaminant information without being overwhelmed with a large number of tests, we developed a 2-tier down selection method to obtain 7 organic airborne contaminants out of a list of more than 260 species for detailed study. The 7 contaminants have different functional groups, including alcohols (isopropanol), nitrogenous compounds (acetonitrile), alkenes (propene), alkynes (acetylene), esters (methyl methacrylate), aromatic rings (naphthalene), and halides (bromomethane) $[3,11]$. According to the in-situ test, the 7 compounds behaved differently in PEMFCs with respect to their contamination and recovery effects. However, the mechanisms for these effects have not yet been explored and the in-situ tests have limited potential for investigating mechanism.

As one of the selected contaminants, methyl methacrylate (MMA) was considered a potential contaminant for the PEMFCs because it is a synthetic precursor for the poly methyl methacrylate acrylic plastics (PMMA) and is also used for the production of the co-polymer methyl methacrylate-butadiene-styrene (MBS), which is used as a modifier for PVC. The maximum outdoor concentration is $2.67 \mathrm{ppb}$ carbon. However, the indoor concentration can be much higher depending on the environment [3]. MMA is considered here as a model ester and therefore it approximates the poisoning effects of other species, which enlarges the impact of this study. According to the in-situ results [3], the PEMFC suffered a significant performance loss in which the steady state dimensionless performance loss was approximately $70-80 \%\left(45^{\circ} \mathrm{C}, 1 \mathrm{~A} \mathrm{~cm}^{-2}, 2 / 2\right.$ stoichiometry, 100/50\% relative humidity, 10/10 $\mathrm{kPag}$ ) in the presence of $20 \mathrm{ppm}$ MMA. Using electrochemical impedance spectroscopy, the decrease in the performance was ascribed to the increase in 
the charge transfer resistance of the ORR and the mass transfer resistance of the $\mathrm{O}_{2}[3]$. However, the detailed mechanism of the effect of MMA on the ORR requires further investigation.

The thin film rotating disk electrode (RDE) methodology has long been used as an indispensable technique for evaluating fuel cell cathode catalysts [12]. The steady state ORR kinetics of the $\mathrm{Pt} / \mathrm{C}$ catalyst can be evaluated at the kinetic-mass transfer mixed controlled region of the ORR curve. The mass transfer behavior can be evaluated in the limiting current region. With the addition of an outer Pt ring to the RDE, the RRDE provides additional information about the ORR mechanism by quantifying the $\mathrm{H}_{2} \mathrm{O}_{2}$ formed on the disk. In this paper, the influence of MMA on the ORR reaction was investigated using the RRDE to provide mechanistic information about the performance loss of the PEMFC. The potentiodynamic measurements from the disk provided us with the coverage and redox information about MMA and, most importantly, correlated it to the ORR kinetic loss. The ring-disk current relationship was further analyzed to clarify the contributions of the 4-electron and 2-electron pathways during the ORR in the presence of MMA. Levich and Tafel plots were used to further confirm the shift in reaction pathway and the change in rate determining step, respectively. The contamination recovery effect was investigated.

\section{Experiments}

\subsection{The preparation of the $\mathrm{Pt} / \mathrm{C}$ catalyst ink and the thin film electrode}

A thin film electrode of the $\mathrm{Pt} / \mathrm{C}$ catalyst was used as the working electrode, the detailed preparation procedure can be found elsewhere [13]. A ring-disk electrode (ALS Co, LTD) 
with glassy carbon as the inner disk $\left(\varnothing=4 \mathrm{~mm}, \mathrm{~A}=0.126 \mathrm{~cm}^{2}\right)$ and polycrystalline $\mathrm{Pt}$ (ID $=5 \mathrm{~mm}, \mathrm{OD}=7 \mathrm{~mm}$ ) as the outer ring was used for each of the tests. A commercially available $46.6 \mathrm{wt} \%$ Pt/C (Ion Power) catalyst was used for all of the electrochemical tests. A $1 \mathrm{mg} / \mathrm{mL}$ catalyst ink was prepared in the solution containing $79.8 \%$ deionized water (18M $\Omega$, Millipore, Super-Q water purification system), 20\% isopropyl alcohol (Fisher Scientific, Certified ACS Plus), and 0.2\% Nafion Solution (10.07 wt.\% Nafion, Ion Power). The Pt loading at the electrode was controlled at $20 \mu \mathrm{g}_{\mathrm{Pt}}$ $\mathrm{cm}^{-2}$ with an appropriate amount of $\mathrm{Pt} / \mathrm{C}$ ink casted on the electrode. The rotational drying method developed by Garsany et al. [12] was used to prepare the thin film and to acquire a uniform dispersion of the catalyst. The collection efficiency of the ring was measured in $2 \mathrm{mmol} / \mathrm{L} \mathrm{K}_{3}\left[\mathrm{Fe}(\mathrm{CN})_{6}\right]$ in a $0.1 \mathrm{~mol} / \mathrm{L} \mathrm{KNO}_{3}$ solution, the collection efficiency was 0.428 .

\subsection{The electrochemical test equipment and conditions}

The as-prepared thin film was used as the working electrode for the ORR in a $0.1 \mathrm{M}$ $\mathrm{HClO}_{4}$ solution. A spiral $\mathrm{Pt}$ wire and an $\mathrm{Ag} / \mathrm{AgCl} / \mathrm{NaCl}(3 \mathrm{M})$ electrode were used as the counter and reference electrodes, respectively. The reference electrode was separated from the test solution by two frits to avoid $\mathrm{Cl}^{-}$contamination. The potentials are reported versus the reversible hydrogen electrode (RHE). The electrochemical measurements were performed using a Biologic VSP Bipotentiostat. The iR-drop correction of the measured potentials was performed by determining the solution resistance (R) using electrochemical impedance spectroscopy (EIS) at $0.57 \mathrm{~V}$ vs RHE [14]. The typical value of $\mathrm{R}$ is $28-31 \mathrm{ohm}$. A correction of $85 \%$ of the $\mathrm{iR}$ drop was made according to the manual from Biologic because positive feedback in the system and too much correction 
would result in system instability. During the tests, the largest current flow was approximately $0.25 \mathrm{~mA}$; therefore, the uncompensated voltage was at most approximately $1 \mathrm{mV}$. The testing temperature was maintained at $30{ }^{\circ} \mathrm{C}$ using a water jacket cell connected to a chiller. The chiller was operated for $20 \mathrm{~min}$ before the test. The RRDE was immersed in an electrochemical cell containing $65 \mathrm{~mL}$ of $\mathrm{HClO}_{4}$ saturated with $\mathrm{N}_{2}$ (ultra Zero $\mathrm{N}_{2}$, Air Gas, purged for at least $20 \mathrm{~min}$ ).

\subsection{The cyclic voltammetry (CV) and ORR measurements}

Initially, the disk potential was cycled 50 times between $0.03 \mathrm{~V}$ and $1.3 \mathrm{~V}$ vs RHE at $500 \mathrm{mV} \mathrm{s}^{-1}$, and the ring potential was cycled 100 times between $0.03 \mathrm{~V}$ and $1.4 \mathrm{~V}$ at $500 \mathrm{mV} \mathrm{s}^{-1}$ to remove any contaminants adsorbed on the surface. CVs were collected between $0.05 \mathrm{~V}$ and $1.03 \mathrm{~V}$ at $20 \mathrm{mV} \mathrm{s}^{-1}$ for 3 cycles, between $0.03 \mathrm{~V}$ and $1.2 \mathrm{~V}$ at $50 \mathrm{mV} \mathrm{s}^{-1}$ for 3 cycles, and between 0.03 and $1.5 \mathrm{~V}$ at $50 \mathrm{mV} \mathrm{s}^{-1}$ for 3 cycles. The initial ORR measurements were collected between $0.05 \mathrm{~V}$ and $1.03 \mathrm{~V}$ at $20 \mathrm{mV} \mathrm{s}^{-1}$ for 3 cycles; the ORR curves were collected using a negative scan initiated at $1.03 \mathrm{~V}$ (the same as the other scans). The last cycle was used for analysis, and the typical rotation rate was 1600 rpm, unless otherwise noted. The MMA (Electron Microscopy Sciences, 99.9\%) effect on both $\mathrm{CV}$ and ORR were tested. Four different concentrations of MMA were tested: $0.1 \mathrm{mM}(0.69 \mu \mathrm{L}$ MMA in $65 \mathrm{~mL}$ electrolyte $), 1 \mathrm{mM}(6.9 \mu \mathrm{L}), 10 \mathrm{mM}(69 \mu \mathrm{L})$, and 100 $\mathrm{mM}(690 \mu \mathrm{L})$. It was determined during the experiments that $30 \mathrm{~min}$ is sufficient to ensure the adsorption equilibrium of the electrode surface. The CV data were collected between $0.05 \mathrm{~V}$ and $1.03 \mathrm{~V}$ at $20 \mathrm{mV} \mathrm{s}^{-1}$ for 10 cycles, followed by cycling between $0.03 \mathrm{~V}-1.2 \mathrm{~V}$ at $50 \mathrm{mV} \mathrm{s}^{-1}$ for 10 cycles, and $0.03 \mathrm{~V}-1.5 \mathrm{~V}$ at $50 \mathrm{mV} \mathrm{s}^{-1}$ for 10 cycles. For the ORR measurements, the contaminant data were collected with potential cycling 
between $0.05 \mathrm{~V}-1.03 \mathrm{~V}$ at $20 \mathrm{mV} \mathrm{s}^{-1}$ for 10 cycles. During the potential cycling on the disk, the ring potential was held at $1.2 \mathrm{~V}$ to collect the $\mathrm{H}_{2} \mathrm{O}_{2}$ that arrived on the ring. To acquire the Levich plot, the ORR was also measured at different rotation speeds, i.e., 400, $900,1600,2500$, and $3600 \mathrm{rpm}$. The recovery effect of the electrode was investigated by rinsing the contaminated electrode with running deionized water for 5 min followed by the transfer of the electrode to a clean cell for further tests. For each test of different concentrations, including both CV and ORR, a new film was prepared. The ORR curves were corrected using the baseline $\mathrm{CV}$ with $\mathrm{CV}$ scans in $\mathrm{N}_{2}$ saturated $0.1 \mathrm{M} \mathrm{HClO}_{4}$ or 0.1 $\mathrm{M} \mathrm{HClO}_{4}+\mathrm{MMA}$, accordingly.

\section{Results and discussions}

\subsection{CV measurements}

Fig. 1 displays the changes in the voltammograms in $0.1 \mathrm{M} \mathrm{HClO}_{4}$ induced by the presence of MMA. Fig. 1a and Fig. 1b show the CVs recorded in the same potential window as the ORR tests and in the extended potential window, respectively. In the presence of $1 \mathrm{mM}$ MMA, CV measurements were recorded for 10 continuous cycles to investigate the cycling effect on the electrode behavior. The electrochemical surface area of the catalyst can be calculated using Equation 1, after correcting for the double layer charging current from Fig. 1a. The correction is performed by deducting the current at $0.40 \mathrm{~V}$ from the total current and assuming that the capacitance is constant at different potentials. The full coverage charge for clean polycrystalline $\mathrm{Pt}$ is $210 \mu \mathrm{C} \mathrm{cm}$, and is used as the conversion factor. The Pt electrochemical surface area $\left(\mathrm{ECSA}_{\mathrm{Pt}}\right)$ is reported in

$\mathrm{m}^{2} \mathrm{~g}_{\mathrm{Pt}}{ }^{-1}$; $\mathrm{Q}$ represents the $\mathrm{H}_{\mathrm{UPD}}$ charges over the range from 0.05 to $0.4 \mathrm{~V}, \mathrm{~L}_{\mathrm{Pt}}$ is the 
working electrode Pt loading $\left(\mathrm{mg}_{\mathrm{Pl}} \mathrm{cm}^{-2}\right)$ and $\mathrm{A}_{\mathrm{g}}\left(\mathrm{cm}^{2}\right)$ is the geometric surface area of the glassy carbon electrode (i.e., $0.126 \mathrm{~cm}^{2}$ ) [15].

$$
\operatorname{ECSA}_{P t}\left(m^{2} g_{P t}^{-1}\right)=\left[\frac{Q_{H-U P D}(C)}{210 \mu C c m_{P t}^{-2} L_{P t}\left(m g_{P t} c m^{-2}\right) A_{g}\left(\mathrm{~cm}^{2}\right)}\right] 10^{5} \text { Equation } 1
$$

The hydrogen desorption peak is used for the calculation, and the number is $83.7 \mathrm{~m}^{2} \mathrm{~g}_{\mathrm{Pt}}{ }^{-1}$ for the clean electrode. At potentials higher than $0.6 \mathrm{~V}, \mathrm{OH}$ adsorption occurs, which is followed by gradual PtO formation with increasing potential. In the presence of $1 \mathrm{mM}$ MMA, the hydrogen desorption peak is suppressed during the forward scan due to the adsorption of MMA. The loss in ECSA is higher for the first cycle (65\% loss) but reaches steady state in the following cycles $(43 \%)$. In the high potential region, the oxidation of MMA occurs and is coupled with Pt oxidation. During the backward scan, the Pt oxide reduction is suppressed to a much larger extent, and the integration of the Pt reduction peak shows an $82 \%$ decrease in the area, corresponding to a higher coverage of MMA in the high potential region. At lower potential, the hydrogen adsorption interferes with hydrogenation of the $\mathrm{C}=\mathrm{C}$ bond [16] in MMA, which leads to a negatively shifted peak potential of $40 \mathrm{mV}$ and an increase in the peak current value. For the CV test in the extended potential window (Fig. 1b), the full scope for the MMA oxidation is investigated. An increase in the MMA oxidation current coupled with Pt oxidation is observed between $0.6-1.1 \mathrm{~V}$, following by a leveling off of the current at $1.4 \mathrm{~V}$. In the backward scan, the PtO reduction peak approaches that of the initial value, which indicates the removal of MMA through oxidation and the formation of PtO at higher potentials. The ECSA measured with the extended potential range approaches the initial 
value, which is consistent with the recapture of the $\mathrm{PtO}$ reduction peak and indicates the successful removal of MMA. This result also indicates that the re-adsorption of MMA on the catalyst surface occurs at a slower rate than its removal rate during cycling.

Fig. 2a shows the $\mathrm{CV}$ results in the presence of MMA at different concentrations, where the concentration varies over four orders of magnitude. A continuous decrease in the hydrogen desorption peak area is observed with the increase in the MMA concentration, indicating an increase in the MMA coverage. In the high potential region, the onset potential for the oxidation of MMA and/or Pt is observed to continuously shift to higher potential with increasing MMA concentration, which is most likely due to the fact that the oxidation of MMA requires the availability of neighboring Pt-OH sites, while an increasing MMA coverage leads to more blockage of the adsorption sites for oxygen containing species on Pt. In the backward scan, this hypothesis is supported because the $\mathrm{PtO}$ reduction peak diminishes with increasing MMA concentration. In the $\mathrm{H}_{\text {UPD }}$ region, the reduction currents for the $\mathrm{C}=\mathrm{C}$ bond increase significantly with increasing MMA concentration, indicating a faster hydrogenation process than the oxidation process in the potential window. The relationship between the MMA concentration and the coverage measured from the hydrogen desorption area and the PtO reduction peak area is plotted in Fig. 2b. The MMA coverage ( $\theta)$ calculated from both the ECSA and the PtO reduction increases with increasing MMA concentration. A Langmuir-type isotherm is observed where the coverage levels off above $10 \mathrm{mM}$. The coverage calculated from the PtO reduction peak is higher than $\mathrm{H}_{\mathrm{UPD}}$, which can most likely be attributed to the influences of the MMA oxidation and hydrogenation on its coverage. 


\subsection{RRDE measurements for the ORR}

Fig. 3 depicts the impact of $1 \mathrm{mM}$ MMA on the ORR of the Pt/C working electrode. The initial ORR curves were recorded for the same working electrode in a clean, airsaturated $0.10 \mathrm{M} \mathrm{HClO}_{4}$ electrolyte prior to the poisoning step. Fig. 3a shows the positive scan of the ORR with 10 consecutive scans collected to determine the MMA effect. The initial ORR curve has a well-defined diffusion limiting current of $1.37 \mathrm{~mA} \mathrm{~cm}{ }^{-2}$ (geometric) at $0.10-0.80 \mathrm{~V}$, followed by a region under mixed kinetic-diffusion control at $0.80 \mathrm{~V}-1.00 \mathrm{~V}$. For the current on the ring, a very small current is observed at E>0 $0.4 \mathrm{~V}$. At more negative potentials, the ring current increases to larger values due to the generation of more $\mathrm{H}_{2} \mathrm{O}_{2}$, caused by the adsorption of $\mathrm{H}_{\text {ads }}$ on the disk. With the introduction of the MMA, the onset and half-wave potential $\left(\mathrm{E}_{1 / 2}\right)$ shift negatively, indicating reduced activity of the Pt/C for the ORR. A decrease in the diffusion limiting current is also observed. The ORR measured at different cycle numbers are superimposed, indicating that the steady state has been reached. From the ORR curve, the kinetic current can be extracted from the mixed kinetic-diffusion region through the mass transfer correction shown in Equation 2 [2]:

$$
1 / i_{K}=1 / i-1 / i_{d} \quad \text { Equation } 2
$$

where $i_{K}$ represents for the mass transfer corrected current (kinetic current), $i$ represents the current on the curve, and $\mathrm{i}_{\mathrm{d}}$ represents the diffusion limiting current measured at 0.60 V. The corrected mass activity (MA) values are calculated with the kinetic current normalized to the catalyst loading and are compared at $0.90 \mathrm{~V}$. The MA value decreases 
from $0.140 \mathrm{~A} \mathrm{mg}_{\mathrm{Pt}}^{-1}$ for the initial electrode to $0.049 \mathrm{~A} \mathrm{mg}_{\mathrm{Pt}}{ }^{-1}$ with $1 \mathrm{mM} \mathrm{MMA}$ in the electrolyte, corresponding to a $65 \%$ loss. This value stays between the ESCA loss from the $\mathrm{H}_{\mathrm{UPD}}$ measurements $(43 \%)$ and the loss of the Pt reduction peak area (82\%), clearly indicating a relationship between the drop in the Pt active surface and the mass activity. Fig. $3 \mathrm{~b}$ shows both the positive and the negative scans for the ORR to look into the effect of the scan direction on the electrode behavior. For both measurements, the oxygen reduction rate is observed to be faster in the positive than the negative scan direction in the kinetic region. The appearance of hysteresis in the ORR curves of the negative scans can be attributed to the higher coverage of the structure sensitive $\mathrm{OH}$ species, which is believed to be a site blocking species for the ORR [17]. As a result, a negative shift by 28 $\mathrm{mV}$ in the half wave potential $\left(\Delta \mathrm{E}_{1 / 2}\right)$ is observed for the negative scan compared with the positive scan for the initial ORR. In the presence of MMA, the $\Delta \mathrm{E}_{1 / 2}$ value decreases to $17 \mathrm{mV}$ despite the total kinetic loss compared with the original ORR curves. The decrease in $\Delta \mathrm{E}_{1 / 2}$ might be attributed to the fact that the $\mathrm{OH}$ coverage is significantly suppressed by the presence of MMA, while the MMA coverage is less sensitive to the potential than $\mathrm{OH}$ in the potential range. A slight difference in the ring current can be observed between the forward and backward scans, which can be ascribed to the slight change in the MMA coverage in the two directions due to the occurrence of oxidation and reduction.

For the shift in the reaction pathway of ORR, i.e., from a 4-electron reduction mechanism (to form water) to a 2-electron reduction (to form $\mathrm{H}_{2} \mathrm{O}_{2}$ ), the percentage of the ORR that occurs through the $\mathrm{H}_{2} \mathrm{O}_{2}$ pathway can be calculated using Equation 3 [9]. 
$\mathrm{X} \mathrm{H}_{2} \mathrm{O}_{2}[\%]=100 \times \frac{2 \times \mathrm{I}_{\mathrm{R}} / \mathrm{N}}{\mathrm{I}_{\mathrm{D}}+\mathrm{I}_{\mathrm{R}} / \mathrm{N}} \quad$ Equation 3

where $I_{\mathrm{R}}$ and $I_{\mathrm{D}}$ are the ring and disk currents, respectively, and $N$ is the collection efficiency of the RRDE (0.428). To confirm that the ring current is mainly from $\mathrm{H}_{2} \mathrm{O}_{2}$, rather than the oxidation of MMA, the ring current was also collected with the disk potential held at the OCV. As shown in the inset of Fig. 3a, the ring current (approximately $1 \mu \mathrm{A}$ ) observed during the measurement can be attributed to the oxidation of MMA, which is rather low compared to what can be observed during potential cycling on the disk. Therefore, it is confirmed that the ring current collected is mainly due to the $\mathrm{H}_{2} \mathrm{O}_{2}$ oxidation.

Fig. 4 shows the percentage of the ORR that occurs through the $\mathrm{H}_{2} \mathrm{O}_{2}$ pathway. An increase in the $\mathrm{H}_{2} \mathrm{O}_{2}$ production is observed at lower potential values; at $0.4 \mathrm{~V}$, the $\mathrm{H}_{2} \mathrm{O}_{2}$ production is $20 \%$ for the MMA contaminated electrode in comparison with $1 \%$ for the clean electrode. As suggested in the literature [18], the adsorption of $\mathrm{O}_{2}$ molecules on $\mathrm{Pt}$ occurs through either a parallel (Griffiths model/bridge model) or an end-on configuration (Pauling model). The theoretical calculations [19] indicated that the chemisorption of $\mathrm{O}_{2}$ appears to be more favorable at the two-fold bridge sites than the ontop sites due to better overlap of the $\mathrm{O}_{2} 2 \sigma_{\mathrm{u}}$ orbital with the Pt surface. While parallel adsorption sites are likely to be involved in the rupture of the $\mathrm{O}-\mathrm{O}$ bond and lead to the overall 4-electron reduction, the end-on adsorption sites are more likely to lead to the formation of $\mathrm{H}_{2} \mathrm{O}_{2}$ due to the single adsorption. On the MMA adsorbed surface, it is proposed that the partial alteration of the reaction pathway can be attributed to the 
restriction of the parallel adsorption mode of $\mathrm{O}_{2}$ on $\mathrm{Pt}$ and the promotion of end-on adsorption, due to the coverage effect of MMA and the reduction in the availability of active and contiguous Pt sites.

As shown in CV spectra in Section 3.1, hydrogenation of the $\mathrm{C}=\mathrm{C}$ bond takes place in the low potential range, with an inflection in reduction curve observed at $\sim 0.25 \mathrm{~V}$ (coupled with $\left.\mathrm{H}_{\mathrm{UPD}}\right)$. In the in-situ PEMFC, such a low potential is unrealistic during the operation. Therefore, we changed the potential range for the ORR measurements to avoid influence of MMA reduction on ORR, as shown in Fig. 5a. It can be observed from the plots that the ORR curves on the disk shift negatively due to the increase in the lower potential limit from $0.05 \mathrm{~V}$ to $0.27 \mathrm{~V}$, suggesting a decrease in the mass activity of the catalyst for ORR. A higher ring current was also collected for the positive scans, indicating that more ORR occurs through a 2-electron reduction pathway. To clarify the influence of the MMA reduction on the ORR pathway, Fig. 5b shows the ring current collected in both the negative and positive directions. The $1^{\text {st }}$ cycle for the ring current in the negative direction from $1.03-0.27 \mathrm{~V}$ was collected immediately after the $10^{\text {th }}$ cycle of the ORR in MMA at $0.05-1.03 \mathrm{~V}$. Because the CVs were collected with the negative scan measured first, the negative scan on the ring for the $1^{\text {st }}$ cycle $(1.03-0.27 \mathrm{~V})$ overlaps the negative scan of the $10^{\text {th }}$ cycle $(0.05-1.03 \mathrm{~V})$. In the following positive scan, the ring current increases by $36 \%$ at $0.4 \mathrm{~V}$ in comparison to the positive scan of the $10^{\text {th }}$ cycle (0.05-1.03 V). This result shows that the $\mathrm{H}_{2} \mathrm{O}_{2}$ production rate increases when the reduction of MMA is avoided. The increase in $\mathrm{H}_{2} \mathrm{O}_{2}$ production is attributed to the increase in MMA coverage on the Pt surface due to the lack of MMA hydrogenation. 
Furthermore, this result is consistent with the coverage observation from the CV spectra, where a lower MMA coverage is found in the $\mathrm{H}_{\mathrm{UPD}}$ region compared with the PtO reduction region, which also indicates a positive effect in lowering the MMA coverage by hydrogenation.

\subsection{ORR charge transfer number}

The charge transfer number of the ORR on the electrode can be evaluated using two parallel methods: the Levich plot and the disk-ring current evaluation. For the Levich plot technique, the ORR curves were measured at different rotation speeds, as shown in Fig. 6a, and the relationship between the current and the rotation speed can be correlated using Equation 4. In the equation, $i_{d}$ is the measured electrode current density in the diffusion limit current region, $\mathrm{n}$ represents the charge transfer number, $\mathrm{F}$ is the Faraday constant $\left(96,485 \mathrm{C} \mathrm{mol}^{-1}\right)$, A is the geometric surface area of the RDE, $\mathrm{c}^{*}$ is the bulk concentration of $\mathrm{O}_{2}\left(1.26 * 10^{-3} * 0.21\right)$, D is the diffusion coefficient of $\mathrm{O}_{2}\left(1.93 * 10^{-5}\right.$ $\left.\mathrm{cm}^{2} \mathrm{~S}^{-1}\right), v$ is the kinematic viscosity of the solution $\left(0.01 \mathrm{~cm}^{2} \mathrm{~S}^{-1}\right)$ and $\omega$ is the angular rotation rate of the electrode. Thus, Equation 4 gives a linear dependence of $i_{d}$ on the square root of $\omega$ [7]. The slope, the so called B-factor, allows one to assess the number of electrons involved in the oxygen reduction reaction [20].

$$
\mathrm{i}_{\mathrm{d}}=0.62 \mathrm{nFAD} \mathrm{D}^{2 / 3} \omega^{1 / 2} \mathrm{v}^{-1 / 6} \mathrm{c}^{*} \quad \text { Equation } 4
$$

The linear Levich plot is shown in Fig. 6b, and the slopes are used to extract the number of charge transfer electrons. The charge transfer number for the initial ORR and the ORR in $1 \mathrm{mM}$ MMA are calculated to be 4.07 and 3.52 , respectively, indicating a shift in 
reaction pathway of ORR from 4-electron reduction to 2 -electron reduction. The percentage of ORR occurring through the $\mathrm{H}_{2} \mathrm{O}_{2}$ route is shown in Fig. 7a and calculated from the ring disk relation. The percentage of the current collected on the ring increases with an increase in the rotation rate, which can be interpreted in the following way: As we know, the collection efficiency test of the RRDE is performed using the redox reaction of $\left[\mathrm{Fe}(\mathrm{CN})_{6}\right]^{4-} /\left[\mathrm{Fe}(\mathrm{CN})_{6}\right]^{3-}$, which is a simple 1-electron reaction. Thus, the collection efficiency is not influenced by the rotation speed. In the ORR, however, the multi-electron transfer reaction coupled with the chemical reaction makes the case more complicated. As shown in Scheme 1 [21], the ORR occurs either through a direct 4electron or a 2-electron reduction pathway. The $\mathrm{H}_{2} \mathrm{O}_{2}$ produced in the 2-electron reduction pathway leaves the surface through 3 different routes, i.e., further reduction to water $\left(\mathrm{k}_{3}\right)$, self-decomposition to $\mathrm{O}_{2}$ and $\mathrm{H}_{2} \mathrm{O}\left(\mathrm{k}_{4}\right)$, and diffusion into the bulk solution $\left(\mathrm{k}_{\text {diff }}\right)$. The ring only collects the part that diffused into the bulk solution. Therefore, an increase in the rotation rate of the electrode increases $\mathrm{k}_{\mathrm{diff}}$ and, therefore, increases the ratio of $\mathrm{k}_{\text {diff }}$ to $\mathrm{k}_{3}$ and $\mathrm{k}_{4}$. As a result, the dependence of the $\mathrm{H}_{2} \mathrm{O}_{2}$ production percentage on the rotation rate is observed. Therefore, to provide accurate evaluation results from the RRDE, several rotational speeds should be measured instead of a single set of data. The charge transfer number (n) can be calculated using Equation 5 [9] from the net ring/disk current. The meaning of $I_{D}, I_{R}$ and $N$ is the same as in Equation 3.

$$
n=4 I_{D} /\left(I_{D}+I_{R} / N\right) \quad \text { Equation } 5
$$


The calculation results are shown in Fig. $7 \mathrm{~b}$ and agree well with the result from Levich plot. Therefore, it is confirmed that $\mathrm{n}$ decreases in presence of MMA due to the partially shift of ORR from the 4-electron reduction to 2-electron reduction.

\subsection{Concentration effect}

To look into the concentration effect of MMA on the ORR reaction, MMA concentrations over 4 orders of magnitude have been tested. Fig. 8 shows the MMA influence on the OCV of the electrode. In the initial Air saturated electrolyte, the OCV value is approximately $1.03 \mathrm{~V}$ for all four electrodes. The much lower OCV values acquired in the clean electrolyte than $\mathrm{E}^{\Theta}$ are attributed to the contribution of the counter balance reactions, such as Pt oxidation and dissolution, which readily balances the sluggish ORR with an exchange current of approximately $10^{-8} \mathrm{~A} \mathrm{~cm}^{-2} \mathrm{Pt}$ [22]. In the contaminated cell, it is proposed that the partial oxidation of MMA balances the ORR exchange current and further decreases the OCV values. In the initial state before MMA reaches equilibrium, a sharp drop in the potential is observed, indicating the high anodic current generated on the clean Pt/C electrode. From CV measurements shown in Fig. 1 (section 3.1), however, it is observed that the potential is not sufficient for the full oxidation of MMA to $\mathrm{CO}_{2}$. As a result, the oxidation current decreases to lower values due to an increase in the MMA coverage, and therefore, the OCVs increase to higher values and reach the steady state after MMA was injected for $1000 \mathrm{~s}$. The OCV values decrease with increasing MMA concentration, which is also attributed to the coverage effect. 
Fig. 9 shows the concentration effect of MMA on the ORR behavior. As shown in Fig. 9a, the increase in the MMA concentration leads to both a negative shift of the ORR curves and an increase in the ring current. In Fig. 9b, the correlation between $\theta$ and the MA loss for ORR at $0.9 \mathrm{~V}$ is plotted, and the $\theta$ values are taken from Fig. 2b. The increase in $\theta$ leads to an increase in the MA loss, indicating that the loss in active surface area is an important factor for the activity loss of the $\mathrm{Pt} / \mathrm{C}$ catalysts. However, the MA loss against MMA coverage plot in Fig. 9c does not follow a linear dependency, which suggests that there are other factors influencing the mass activity for the ORR. Another MMA impact leading to the MA loss is a change in the catalyst work function. It was found that the polarization potential of an electrode toward an electrochemical reaction is inherently correlated with the change in the electron work function $(\Phi)$ of the electrode [9]. $\Phi$ is sensitive to changes in the surface of the electrode, and the adsorption of a contaminant would greatly alter the energy needed to remove an electron from the catalyst surface to a state at rest near the surface. The change in $\Phi$ is expressed in Equation $6[9,23,24]$ :

$$
\Phi=\Phi_{0}-4 \pi s \mu \quad \text { Equation } 6
$$

where $\Phi_{0}$ is the work function of the bare metal surface, s is the surface concentration of the adsorbent on the catalyst per unit area, and $\mu$ is the dipole moment of the adsorbed molecule. As shown in Fig. 9b, the increase in the MMA concentration results in an increase in s (proportional to $\theta$ ) on the Pt and, therefore, a linear relationship between the change in the work function of $\operatorname{Pt}\left(\Phi-\Phi_{0}\right)$ and $\theta$ is expected. The benefit of Equation 6 is it shows the relationship between the work function and the surface coverage with a slope 
that is related to a characteristic of the contaminant $(\mu)$. However, its limitation lies in the insufficiency in quantitative calculation. On the ring, an increase in $\mathrm{H}_{2} \mathrm{O}_{2}$ production is observed with increasing MMA concentration/coverage. As shown in Fig. 10, the $\mathrm{H}_{2} \mathrm{O}_{2}$ production increases from $9 \%$ to $35 \%$ at $0.4 \mathrm{~V}$ due to the inhibition of the 4-electron reduction and decrease in $n$. As shown in Fig. 9, $i_{d}$ decreases concurrently with an increase in the MMA concentration. A decrease in the diffusion limiting current in the presence of contaminants can be ascribed to a decrease in $\mathrm{n}$ and/or a change in the oxygen transport properties of the electrolyte. The contribution of the ring current to the $\mathrm{i}_{\mathrm{d}}$ loss is calculated at $0.4 \mathrm{~V}$ with the following equation: $100 \% \times\left(\mathrm{i}_{\mathrm{R}} / \mathrm{N}\right) /\left(\mathrm{i}_{\mathrm{d} \text { initial }}-\mathrm{i}_{\mathrm{d}}\right.$ MMA $)$. Results are shown in Fig. 10b. At concentrations below $10^{-2} \mathrm{M}$, a decrease in $\mathrm{n}$ leads to a major decrease in $\mathrm{i}_{\mathrm{d}}(81 \pm 4 \%)$. However, at $10^{-1} \mathrm{M}$, the high concentration of the MMA may also influence the solubility of $\mathrm{O}_{2}$ in the electrolyte $\left(\mathrm{c}^{*}\right)$, the viscosity of the electrolyte $(v)$, and/or the diffusion coefficient of the $\mathrm{O}_{2}(\mathrm{D})$ in Equation 4; therefore, the decrease in $n$ accounts for only $50 \%$ of the $i_{d}$ loss, and the rest of the $i_{d}$ losses can be attributed to changes in the $\mathrm{O}_{2}$ transport properties. Similar mass transport effects have been observed in the literature due to the presence of ionic impurities in solutions $[25,26]$. The increase in mass transfer resistance for the ORR was also observed in the in-situ cell test in the presence of MMA, in which the mechanism is proposed to be different from the one we propose here due to the different operating conditions [27].

\subsection{Tafel slope evaluation}

Fig. 11 shows the mass-transport corrected Tafel plots of the ORR measurements, and the correction is made using Equation 2. The current range of 0.2 to $0.8 \mathrm{i}_{\mathrm{d}}$ is selected for 
the Tafel slope evaluation to ensure the accuracy of the RDE mass-transport corrections. For the initial ORR, a slope of $71 \mathrm{mV} / \mathrm{dec}$ is observed, which corresponds to $2.3 \mathrm{RT} / \mathrm{F}$ and indicates the first charge transfer process as the rate determining step [2, 20], as shown in Equations 7 and 8.

$\mathrm{O}_{2}+\mathrm{Pt} \rightarrow \mathrm{Pt}\left(\mathrm{O}_{2}\right)$ ads $\quad$ Equation 7

$\mathrm{Pt}\left(\mathrm{O}_{2}\right)$ ads $+\mathrm{e}-\rightarrow \mathrm{Pt}\left(\mathrm{O}_{2}{ }^{-}\right)$ads (rds) Equation 8

With the adsorption of MMA at difference concentrations, a break in the slope can be observed with lower values at the high potentials and higher values at low potentials. At higher MMA concentrations, Tafel slopes with higher values are observed, which approach $200 \mathrm{mV} / \mathrm{dec}$ in the low potential range in the presence of $0.1 \mathrm{M}$ MMA. The decrease in the kinetic current indicates the increasing retardation effect of the MMA on the ORR with increasing concentration, and the change in the Tafel slope shows the change in mechanism of the ORR. In the literature, a Tafel slope of $60-120 \mathrm{mV} / \mathrm{dec}$ is frequently used to confirm the first charge transfer reaction as the rate determining step of the ORR $[9,20,24]$. In our case, the increase in the Tafel slope with increasing MMA concentrations may suggest that the rate determining step(RDS) for the ORR has been altered to other possible steps in the presence of high MMA coverage on the Pt. Qualitatively, the sluggish nature of the ORR and the specific adsorption of the MMA lead to the change in the Tafel plot: i) The specific adsorption of MMA in the inner Helmholtz plane (IHP) leads to a change in the double layer structure at the electrode interface, where the charge transfer kinetics and Tafel slope are frequently observed to be 
influenced [28]; ii) The surface electronic structure of Pt is altered due to the electron donation effects of the conjugated $\pi$ bonds in MMA; therefore, the adsorption energy of $\mathrm{O}_{2}$ may also be altered; iii) As the oxidation of MMA occurs in the same potential range as the ORR, the above changes are expected to be potential dependent. As a result, the transfer of electrons for the ORR at the electrode surface is altered by the above factors, and a change in the Tafel slope is observed with increasing MMA coverage.

\subsection{Recovery effect}

Fig. 12 shows the results of the attempts to recover the performance of the $\mathrm{Pt} / \mathrm{C}$ electrodes. A water rinsing process was used to remove the adsorbed MMA from the surface after the CV and ORR tests in the presence of MMA. During the electrode transfer and rinsing process, special care was taken to ensure that the electrode was always covered with a drop of water, which prevented the electrode from direct contact with air. Fig. 12a shows the ORR curve of the recovered electrode in comparison to the initial ORR curve. Results indicate that the recovered electrode has a ORR curve that is almost superimposed over the initial curve. An $84 \%$ recovery was acquired by carefully calculating and comparing the mass activity at $0.9 \mathrm{~V}$, suggesting the presence of trace amounts of MMA on the electrode after the water rinse and the potential cycles between 0.05 and $1.03 \mathrm{~V}$. A higher current on the ring was observed for the recovered electrode, confirming the presence of MMA residuals on the electrode. The CV measurements were carried out to investigate the recovery of ECSA, 10 cycles were measured in the potential range of $0.05-1.03 \mathrm{~V}$ and $0.03-1.2 \mathrm{~V}$. From the calculation of the $\mathrm{H}_{\mathrm{UPD}}$ area, the ECSA recovers to $88 \%$ of the original value after the $10^{\text {th }}$ cycle for the potential cycling between 
0.05-1.03 V. This result is fairly consistent with the mass activity results from the ORR measurements. Therefore, the loss of the mass activity can be attributed to the loss in ECSA. Further recovery of the ECSA value to $97 \%$ is observed when the CV cycling is performed over the range of $0.03-1.2 \mathrm{~V}$ vs RHE, indicating sufficient removal of the MMA residuals from the Pt surface over a wider potential window.

\section{Conclusion}

The effect of MMA at different concentrations on the $\mathrm{Pt} / \mathrm{C}$ catalyst performance for ORR was investigated using the RRDE method. The coverage of MMA on Pt increases with increasing MMA concentration. The kinetics of the ORR slows down with the increase in MMA coverage. At high MMA concentrations, the mass transfer properties of $\mathrm{O}_{2}$ are also altered. This might be attributed to the decreases in the $\mathrm{O}_{2}$ solubility, mass transfer coefficient, and/or kinematic viscosity. The alterations in the mass transfer properties of $\mathrm{O}_{2}$ resulted in a decrease in the diffusion limiting current. The production of $\mathrm{H}_{2} \mathrm{O}_{2}$ increases greatly in the presence of MMA due to the shift in the reaction pathway from a 4-electron to a 2-electron mechanism. As a result, the decrease in the total charge transfer number is observed in both the ring-disk current evaluation and the Levich plot. An increase in the Tafel slope is observed, and the value increases with increasing concentration of MMA, which indicates that the passage of electrons during the ORR at the electrode surface is altered by the adsorption of MMA. A partial recovery was obtained by rinsing the electrode followed by potential cycles between 0.05 and $1.03 \mathrm{~V}$. The remaining MMA on the surface can be removed by cycling over a wider potential window. The current study provides the following insights into the contamination effect of MMA on in-situ PEMFCs: i) A decrease of the performance of the PEMFC can be 
attributed to the coverage of the MMA on the Pt surface, which results in a decrease in the ORR kinetics. ii) The mass transfer properties of the $\mathrm{O}_{2}$ are also influenced at elevated concentrations. iii) MMA sticks to the Pt electrode and only partial recovery can be obtained using a water rinsing process. The full recovery of the MMA is only attainable at $1.2 \mathrm{~V}$ at $30{ }^{\circ} \mathrm{C}$, which indicates that other recovery factors (e.g., rising temperature and prolonged recovery period) need to be considered for their role in PEMFC contamination. iv) The fact that more $\mathrm{H}_{2} \mathrm{O}_{2}$ molecules are produced suggests an undetermined influence of MMA on the durability of the MEA because $\mathrm{H}_{2} \mathrm{O}_{2}$ is known to attack the Nafion ionomer and facilitate polymer decomposition [29]. Therefore, the long-term effect of MMA on the cathode material in PEMFCs is another factor to be considered. As mentioned in the introduction, 7 organic airborne contaminants encompassing different functional groups were selected for detailed studies using a RRDE. The MMA effect is both similar and different in terms of catalyst coverage, catalyst MA, ORR reaction pathway, ORR RDS, concentration dependence, potential dependence, and recovery outcome to other contaminants [30-31]. A comparison of the 7 contaminants effects is planned as a separate paper to summarize mechanisms which will include results obtained with other characterization methods (segmented cell, gas chromatography, and membrane conductivity cell).

\section{Acknowledgements}

This work is supported by the Department of Energy (DE-EE0000467). The test equipment is supported by the Office of Naval Research (N00014-11-1-0391). The 
authors are also grateful to the Hawaiian Electric Company for their ongoing support in the operation of the Hawaii Sustainable Energy Research Facility.

\section{References}

[1] Gasteiger HA, Kocha SS, Sompalli B, Wagner FT. Activity benchmarks and requirements for Pt, Pt-alloy, and non-Pt oxygen reduction catalysts for PEMFCs. Appl Catal B-Environ. 2005;56:9-35.

[2] Zhai Y, Bethune K, Bender G, Rocheleau R. Analysis of the SO2 Contamination Effect on the Oxygen Reduction Reaction in PEMFCs by Electrochemical Impedance Spectroscopy. J Electrochem Soc. 2012;159:B524-B30.

[3] St-Pierre J, Zhai Y, Angelo MS. Effect of Selected Airborne Contaminants on PEMFC Performance. J Electrochem Soc. 2014;161:F280-F90.

[4] Baturina OA, Gould BD, Garsany Y, Swider-Lyons KE. Insights on the SO2 poisoning of $\mathrm{Pt} 3 \mathrm{Co} / \mathrm{VC}$ and $\mathrm{Pt} / \mathrm{VC}$ fuel cell catalysts. Electrochimica Acta. 2010;55:6676-86.

[5] Gould BD, Baturina OA, Swider-Lyons KE. Deactivation of Pt/VC proton exchange membrane fuel cell cathodes by SO2, H2S and COS. J Power Sources. 2009;188:89-95.

[6] Nagahara Y, Sugawara S, Shinohara K. The impact of air contaminants on PEMFC performance and durability. J Power Sources. 2008;182:422-8. 
[7] Rahman MR, Awad MI, Kitamura F, Okajima T, Ohsaka T. A comparative study of $\mathrm{ORR}$ at the $\mathrm{Pt}$ electrode in ammonium ion-contaminated $\mathrm{H} 2 \mathrm{SO} 4$ and $\mathrm{HClO} 4$ solutions. J Power Sources. 2012;220:65-73.

[8] Zhai Y, Bender G, Dorn S, Rocheleau R. The Multiprocess Degradation of PEMFC Performance Due to Sulfur Dioxide Contamination and Its Recovery. J Electrochem Soc. 2010;157:B20-B6.

[9] El-Deab MS, Kitamura F, Ohsaka T. Impact of acrylonitrile poisoning on oxygen reduction reaction at Pt/C catalysts. J Power Sources. 2013;229:65-71.

[10] Garsany Y, Dutta S, Swider-Lyons KE. Effect of glycol-based coolants on the suppression and recovery of platinum fuel cell electrocatalysts. J Power Sources. 2012;216:515-25.

[11] St-Pierre J, Zhai YF, Angelo M. Quantitative ranking criteria for PEMFC contaminants. International Journal of Hydrogen Energy. 2012;37:6784-9.

[12] Garsany Y, Singer IL, Swider-Lyons KE. Impact of film drying procedures on RDE characterization of $\mathrm{Pt} / \mathrm{VC}$ electrocatalysts. Journal of Electroanalytical Chemistry. 2011;662:396-406.

[13] Garsany Y, Ge JJ, St-Pierre J, Rocheleau R, Swider-Lyons KE. Analytical Procedure for Accurate Comparison of Rotating Disk Electrode Results for the Oxygen Reduction Activity of Pt/C. J Electrochem Soc. 2014;161:F628-F40. 
[14] van der Vliet D, Strmcnik DS, Wang C, Stamenkovic VR, Markovic NM, Koper MTM. On the importance of correcting for the uncompensated Ohmic resistance in model experiments of the Oxygen Reduction Reaction. Journal of Electroanalytical Chemistry. 2010;647:29-34.

[15] Garsany Y, Baturina OA, Swider-Lyons KE, Kocha SS. Experimental Methods for Quantifying the Activity of Platinum Electrocatalysts for the Oxygen Reduction Reaction. Anal Chem. 2010;82:6321-8.

[16] Beltowska-Brzezinska M, Luczak T, Baltruschat H, Muller U. Propene oxidation and hydrogenation on a porous platinum electrode in acidic solution. J Phys Chem B. 2003;107:4793-800.

[17] Zecevic SK, Wainright JS, Litt MH, Gojkovic SL, Savinell RF. Kinetics of O2 Reduction on a Pt Electrode Covered with a Thin Film of Solid Polymer Electrolyte. J Electrochem Soc. 1997;144:2973-82.

[18] Lipkowski J, Ross PN. Electrocatalysis: Wiley; 1998.

[19] Chan AWE, Hoffmann R, Ho W. Theoretical aspects of photoinitiated chemisorption, dissociation, and desorption of oxygen on platinum(111). Langmuir. 1992;8:1111-9.

[20] Markovic NM, Gasteiger HA, Grgur BN, Ross PN. Oxygen reduction reaction on $\operatorname{Pt}(111)$ : effects of bromide. Journal of Electroanalytical Chemistry. 1999;467:157-63. 
[21] Markovic NM, Schmidt TJ, Stamenkovic V, Ross PN. Oxygen Reduction Reaction on Pt and Pt Bimetallic Surfaces: A Selective Review. Fuel Cells. 2001;1:105-16.

[22] Gasteiger HA, Gu W, Makharia R, Mathias MF, Sompalli B. Handbook of Fuel Cells-Fundamentals, Technology and Applications: John Wiley\& Sons, Ltd.; 2010.

[23] Schmickler W. The surface dipole moment of species adsorbed from a solution. Journal of Electroanalytical Chemistry and Interfacial Electrochemistry. 1988;249:25-33.

[24] El-Deab MS, Kitamura F, Ohsaka T. Poisoning Effect of Selected Hydrocarbon Impurities on the Catalytic Performance of Pt/C Catalysts towards the Oxygen Reduction Reaction. J Electrochem Soc. 2013;160:F651-F8.

[25] Durst J, Chatenet M, Maillard F. Impact of metal cations on the electrocatalytic properties of Pt/C nanoparticles at multiple phase interfaces. Phys Chem Chem Phys. 2012;14:13000-9.

[26] Okada T, Ayato Y, Dale J, Yuasa M, Sekine I, Asbjornsen OA. Oxygen reduction kinetics at platinum electrodes covered with perfluorinated ionomer in the presence of impurity cations Fe3+, Ni2+ and Cu2+. Phys Chem Chem Phys. 2000;2:3255-61.

[27] St-Pierre J, Ge J, Zhai Y, Reshetenko TV, Angelo M. PEMFC Cathode Contamination Mechanisms for Several VOCs - Acetonitrile, Acetylene, Bromomethane, Iso-Propanol, Methyl Methacrylate, Naphthalene and Propene. ECS Transactions. 2013;58:519-28. 
[28] Okada T, Dale J, Ayato Y, Asbjørnsen OA, Yuasa M, Sekine I. Unprecedented Effect of Impurity Cations on the Oxygen Reduction Kinetics at Platinum Electrodes Covered with Perfluorinated Ionomer. Langmuir. 1999;15:8490-6.

[29] Ono K, Yasuda Y, Sekizawa K, Takeuchi N, Yoshida T, Sudoh M. Evaluation of $\mathrm{Pt} / \mathrm{C}$ catalyst degradation and $\mathrm{H} 2 \mathrm{O} 2$ formation changes under simulated PEM fuel cell condition by a rotating ring-disk electrode. Electrochimica Acta. 2013;97:58-65.

[30] Ge J, St-Pierre J, Zhai Y. PEMFC Cathode Catalyst Contamination Evaluation with a RRDE- Acetylene. Electrochimica Acta. 2014;133:65-72.

[31] Ge J, St-Pierre J, Zhai Y. PEMFC cathode catalyst contamination evaluation with a RRDE-Acetonitrile. Electrochimica Acta. 2014;134:272-80. 
Figure captions:

Figure 1. CV scans in the initial clean cell and the cell containing 1 mM MMA. a) 0.03$1.03 \mathrm{~V}$ vs RHE, 10 cycles, $20 \mathrm{mV} / \mathrm{s}$; b) $0.03-1.5 \mathrm{~V}$ vs RHE, 10 cycles, $50 \mathrm{mV} / \mathrm{s}$. Cycles 1 , 5, and 10 are shown in the figures.

Figure 2. a) $\mathrm{CV}$ measurements in the presence of MMA at various concentrations; b) MMA coverage evaluated through the loss in ECSA and the PtO reduction peak area.

Figure 3. a) ORR curves measured on the disk (positive scans, air, $30^{\circ} \mathrm{C}, 20 \mathrm{mV} / \mathrm{s}, 10$ cycles) and corresponding ring currents (potential holds at $1.2 \mathrm{~V}$ ) measured in the initial clean cell and a cell with $1 \mathrm{mM}$ MMA; b) The RRDE measurements of ORR curves with both scan direction shown. The inset in Fig. 3a shows the ring current measured with potential fixed at $1.2 \mathrm{~V}$ with the presence of MMA and the disk hold at OCV in Air.

Figure 4. The percentage of the ORR that occurs through the $\mathrm{H}_{2} \mathrm{O}_{2}$ pathway. The potential axis corresponds to the potential on the disk.

Figure 5. a) The ORR measured over two potential ranges $(0.05-1.03 \mathrm{~V}$ and $0.27-1.03 \mathrm{~V}$, positive scans). b) The ring current was collected for scans in both the negative and positive directions.

Figure 6. a) The ORR curves measured at different electrode rotation speeds; b) The Levich plots. 
Figure 7. a) The percentage of the ORR occurs through the $\mathrm{H}_{2} \mathrm{O}_{2}$ pathway at various rotation speeds. The potential axis corresponds to the potential on the disk; b) The charge transfer number calculated from the ring-disk current equation.

Figure 8. The concentration effect of the MMA on the OCV.

Figure 9. a) The concentration effect of the MMA on the ORR curves and the collected ring current; b) The correlation between the MMA surface coverage and the mass activity loss measured at $0.9 \mathrm{~V}$; c) The dependency of MA loss as a function of MMA coverage (obtained from $\mathrm{H}_{\mathrm{UPD}}$ and $\mathrm{PtO} / \mathrm{OH}$ reduction) on the electrode.

Figure 10. a) The concentration effect of the MMA on the ORR $\mathrm{H}_{2} \mathrm{O}_{2}$ percentage produced; b) The contribution of the ring current to the $i_{d}$ loss. The calculation is performed at $0.4 \mathrm{~V}$, and a Gaussian fit was used for the fitting.

Figure 11. The Tafel plots for the ORR.

Figure 12. The recovery effect on the electrode: a) the recovery of the ORR on the disk and the ring; b) the recovery of the ECSA at different cycles and in different potential windows. 
Figures:
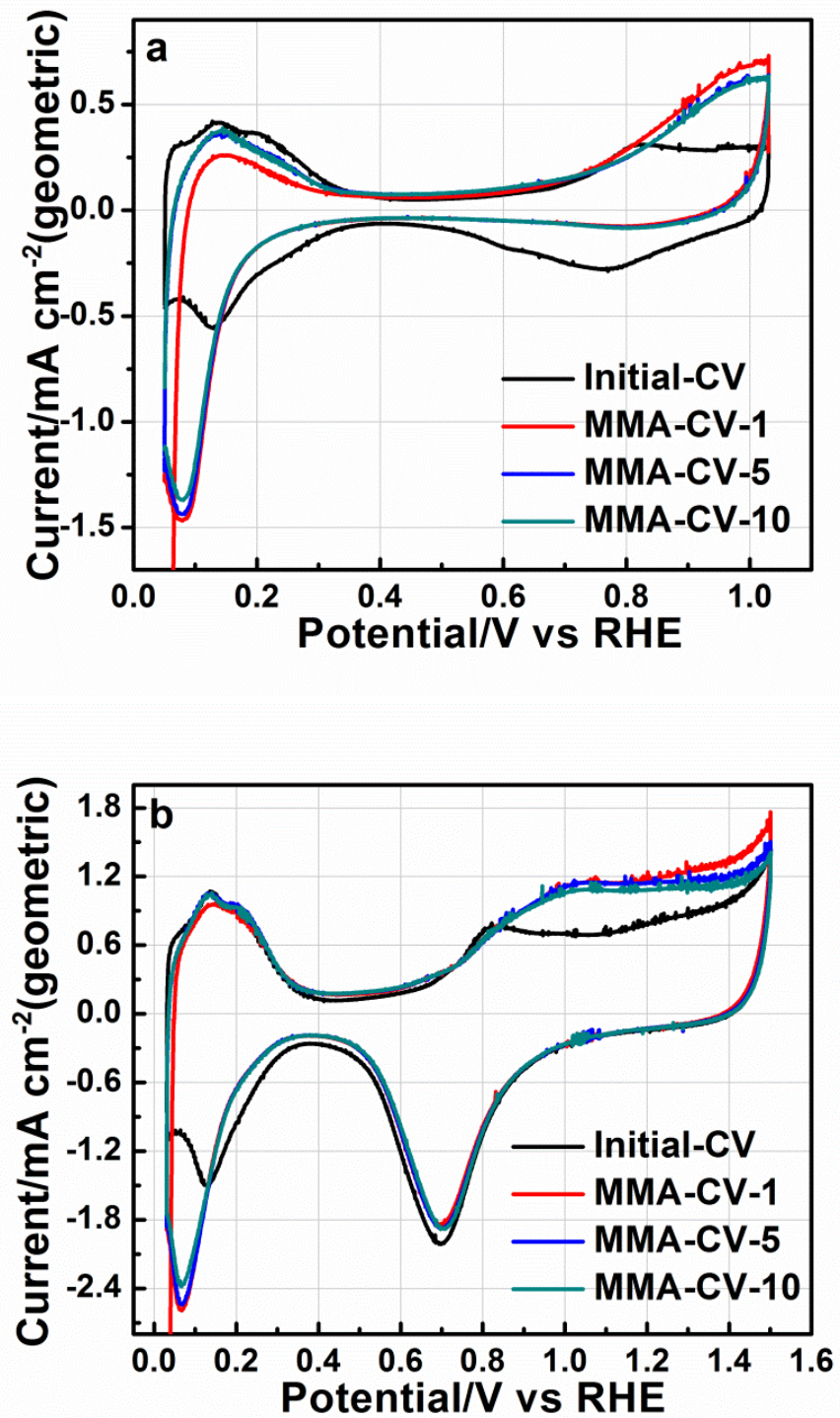
Figure 1. CV scans in the initial clean cell and the cell containing 1 mM MMA. a) 0.03$1.03 \mathrm{~V}$ vs RHE, 10 cycles, $20 \mathrm{mV} / \mathrm{s}$; b) 0.03-1.5 V vs RHE, 10 cycles, $50 \mathrm{mV} / \mathrm{s}$. Cycles 1 , 5 , and 10 are shown in the figures.
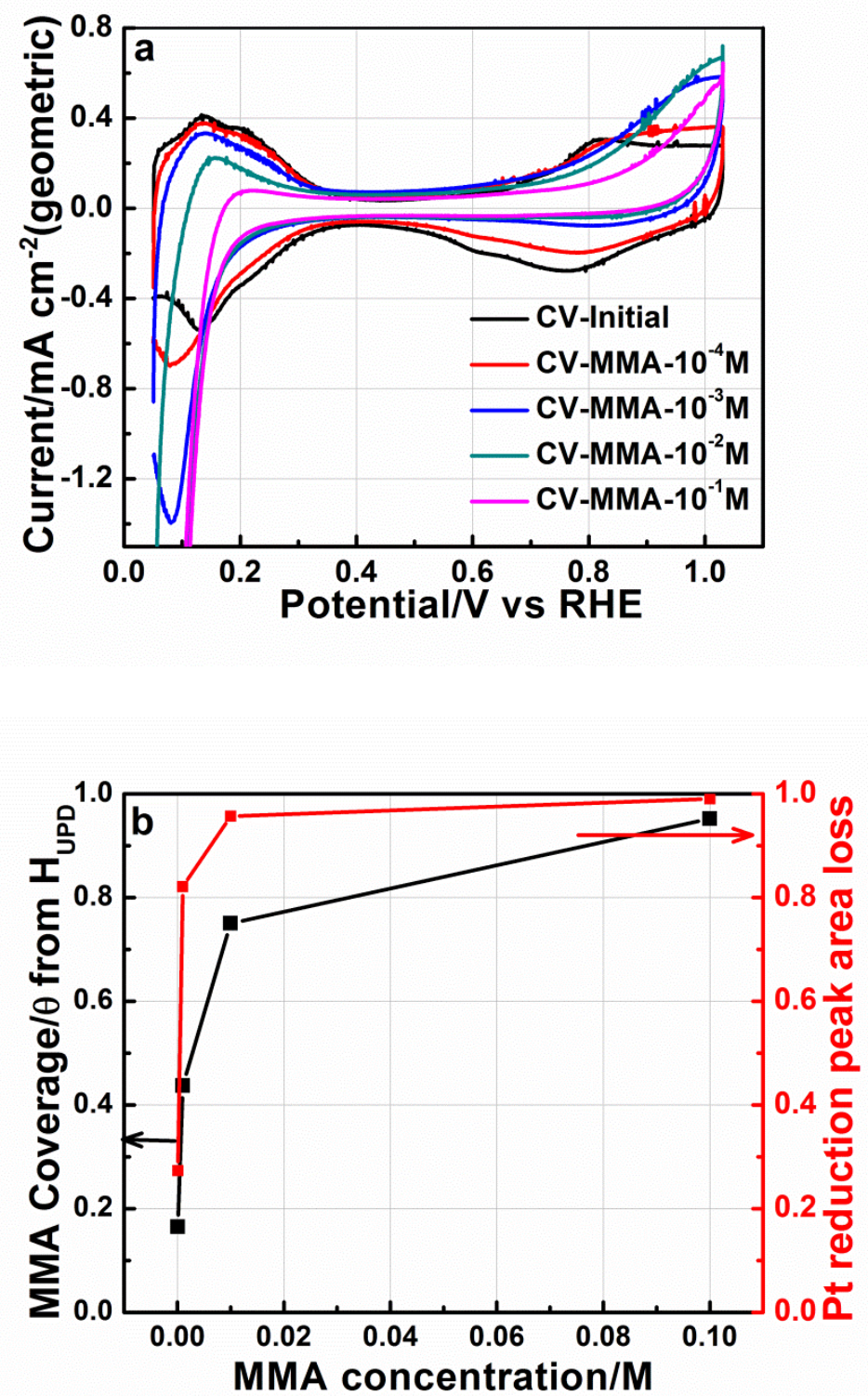
Figure 2. a) CV measurements in the presence of MMA at various concentrations; b) The MMA coverage evaluated through the loss in ECSA and the PtO reduction peak area.
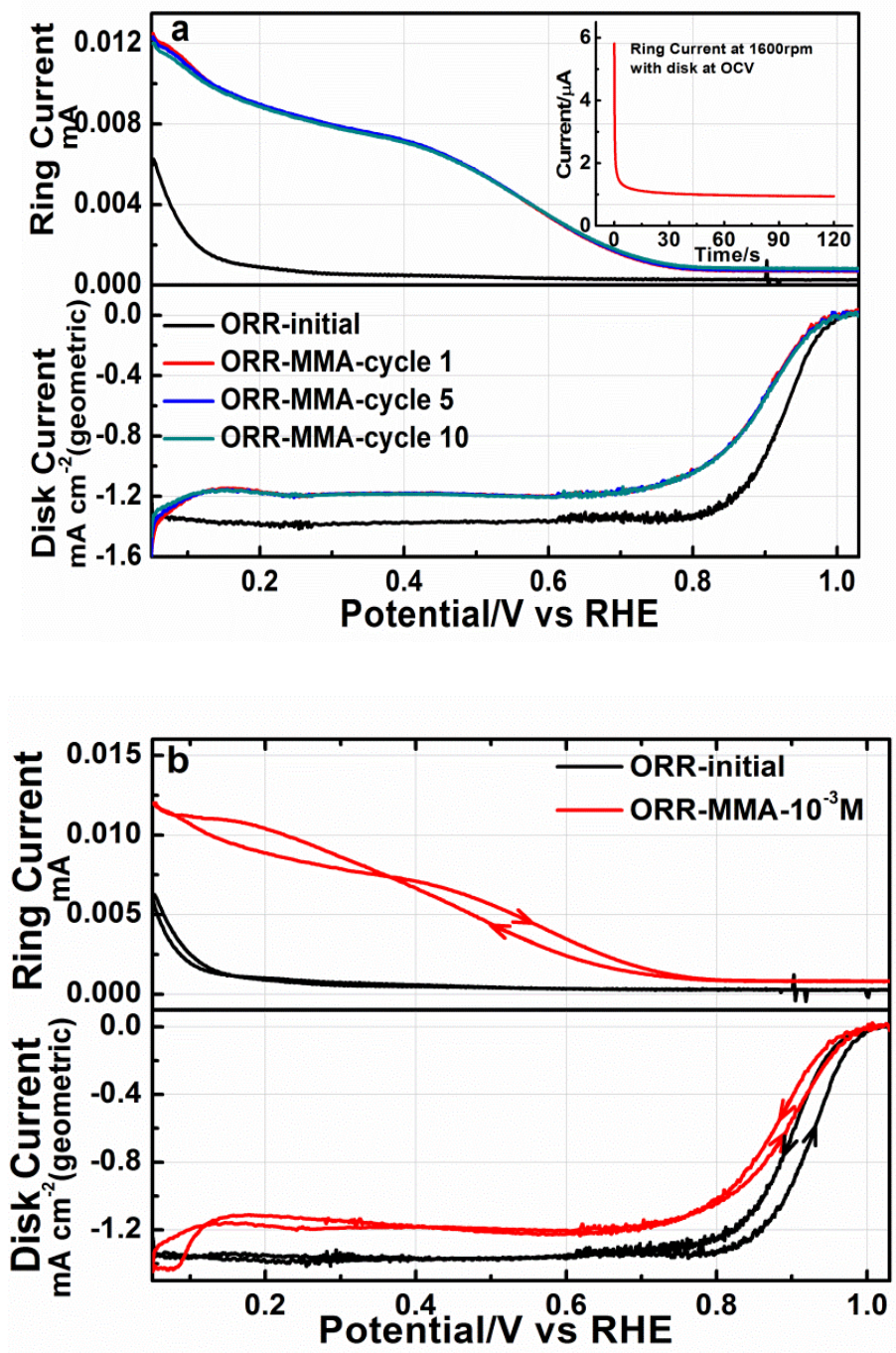

Figure 3. a) ORR curves measured on the disk (positive scans, air, $30^{\circ} \mathrm{C}, 20 \mathrm{mV} / \mathrm{s}, 10$ cycles) and corresponding ring currents (potential holds at $1.2 \mathrm{~V}$ ) measured in the initial 
clean cell and the cell with $1 \mathrm{mM}$ MMA; b) The RRDE measurements of ORR curves with both scan direction shown. The inset in Fig. 3a shows the ring current measured with potential fixed at $1.2 \mathrm{~V}$ with the presence of MMA and the disk hold at OCV in Air.

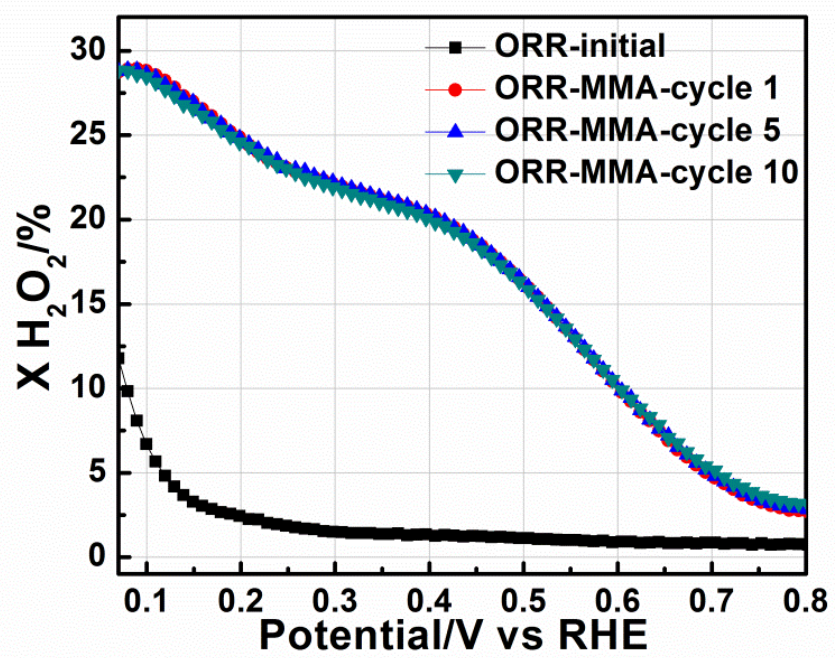

Figure 4. The percentage of the ORR that occurs through the $\mathrm{H}_{2} \mathrm{O}_{2}$ pathway. The potential axis corresponds to the potential on the disk. 

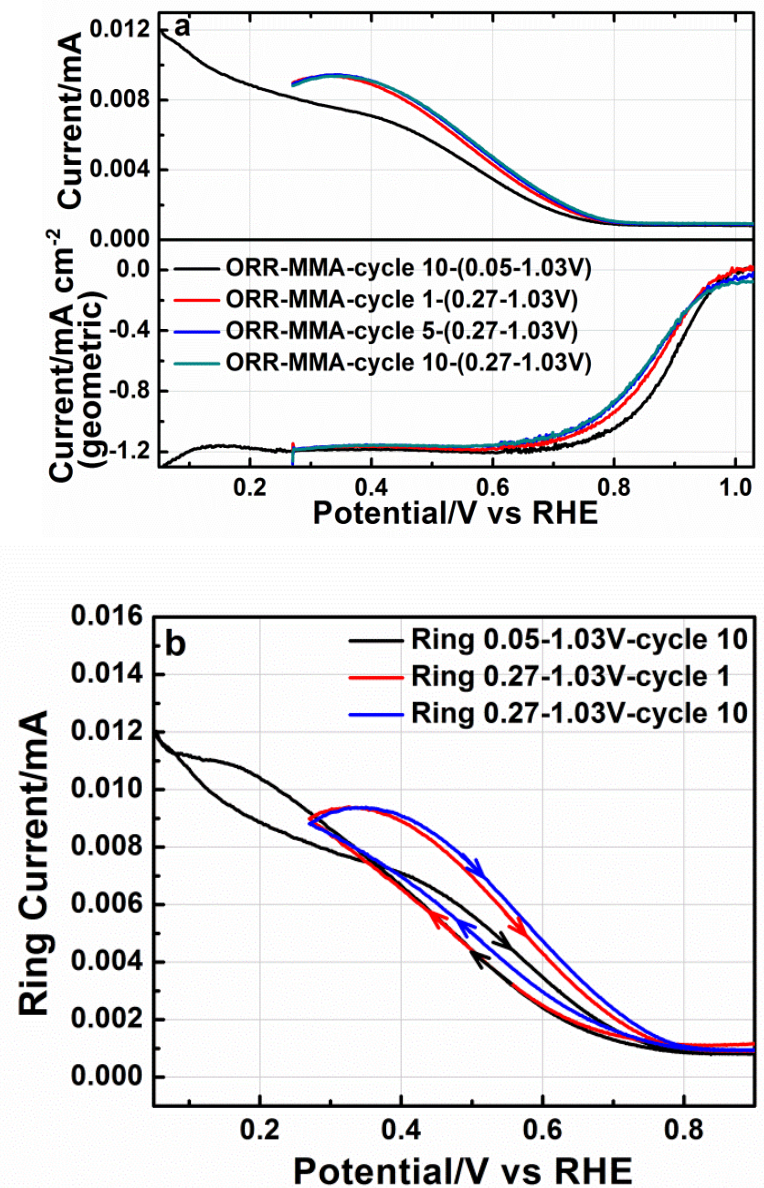

Figure 5. a) The ORR measured over two potential ranges (0.05-1.03 V and 0.27-1.03 V, positive scans); b) The ring current was collected for scans in both the negative and positive directions. 

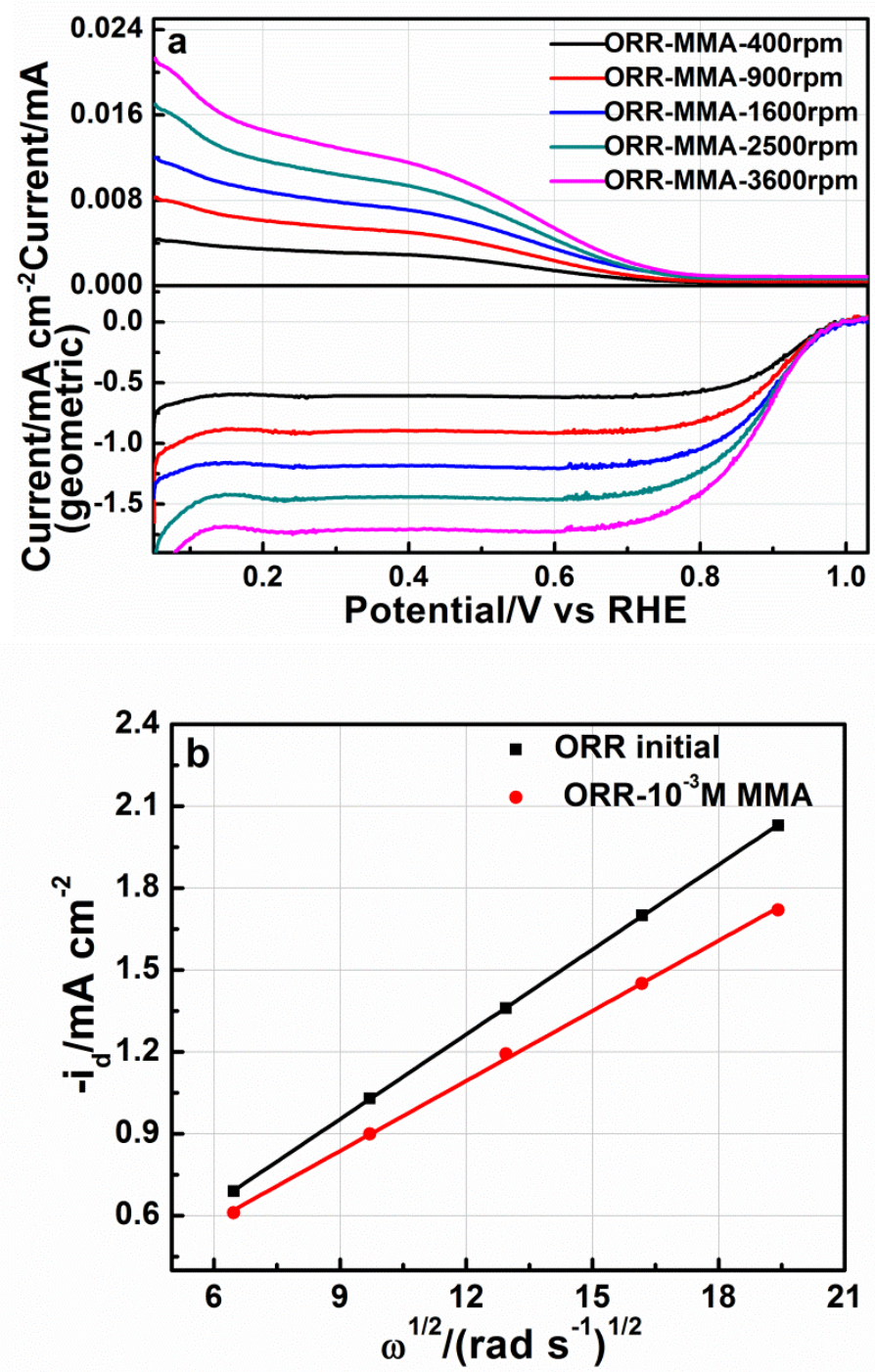
Figure 6. a) The ORR curves measured at different electrode rotation speeds; b) The Levich plots.
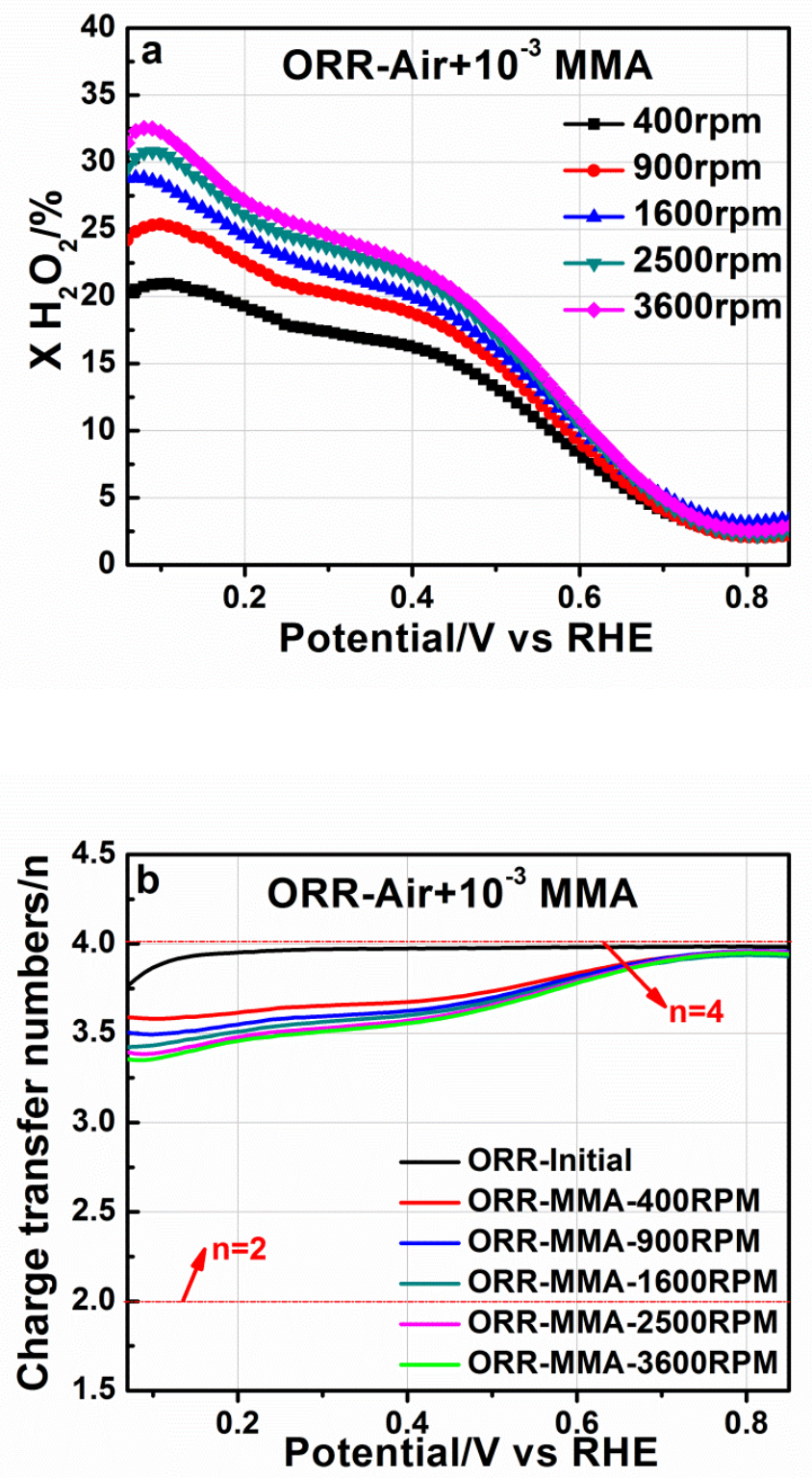
Figure 7. a) The percentage of the ORR occurs through the $\mathrm{H}_{2} \mathrm{O}_{2}$ pathway at various rotation speeds. The potential axis corresponds to the potential on the disk; b) The charge transfer number calculated using the ring-disk current equation.

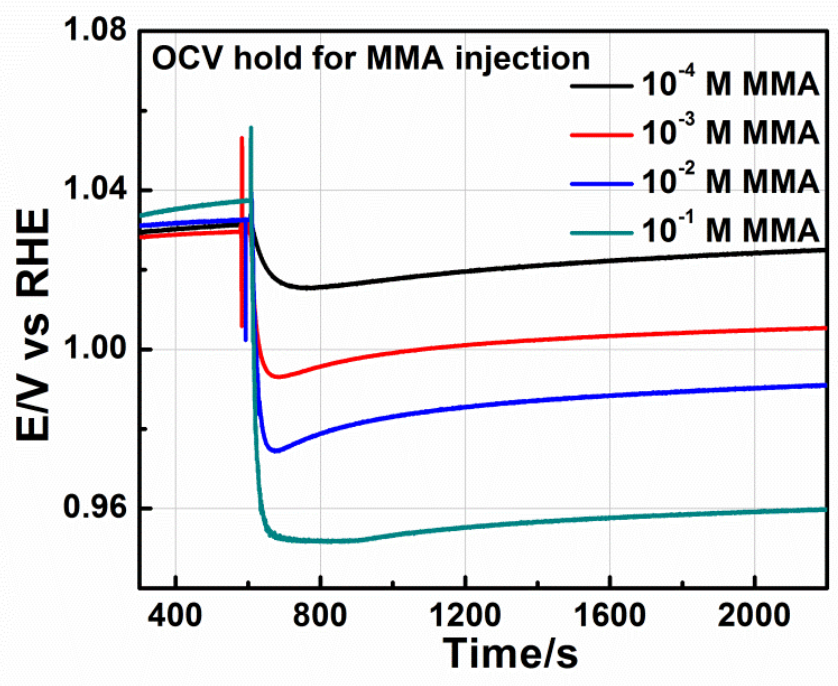

Figure 8. The concentration effect of the MMA on the OCV. 

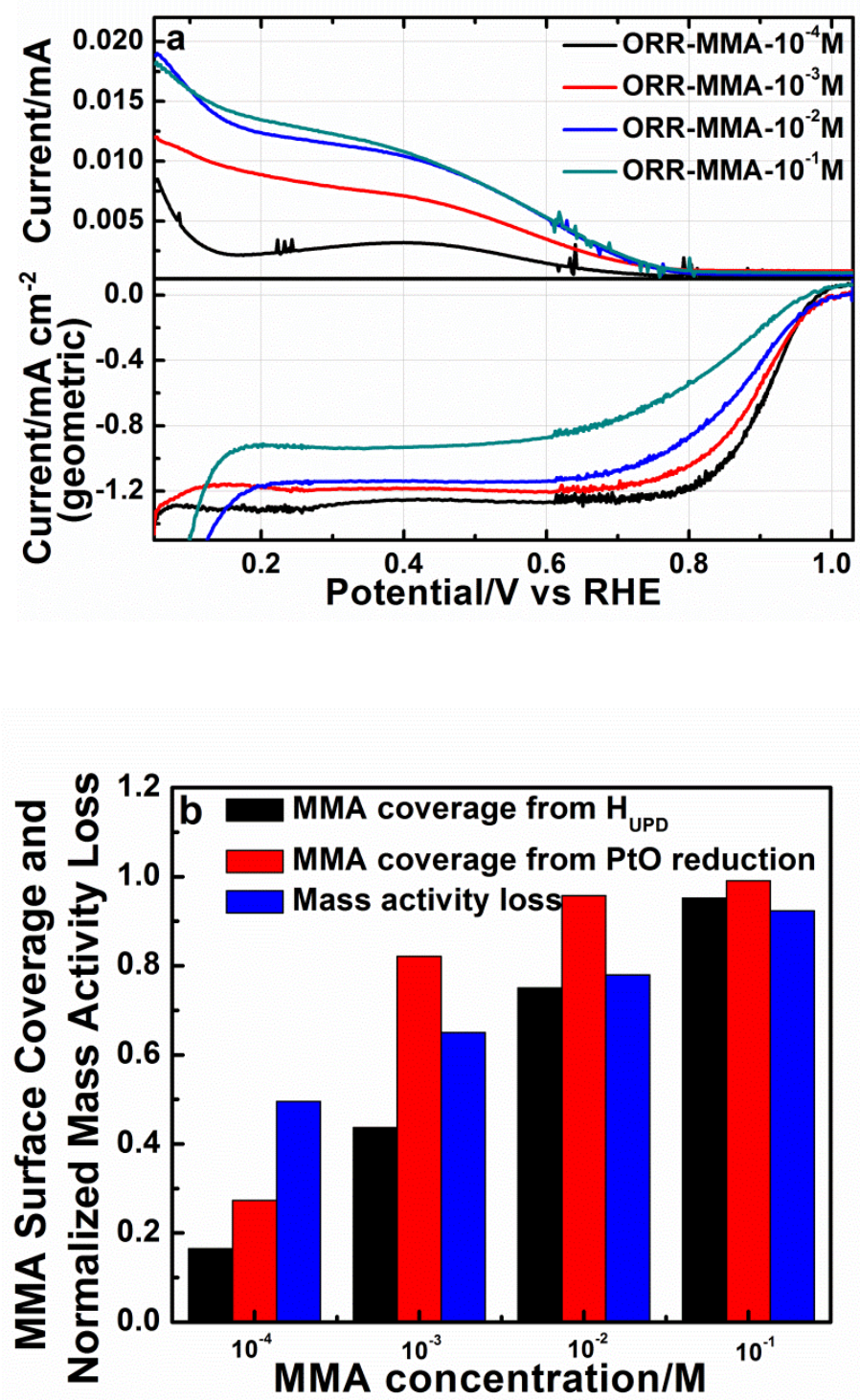


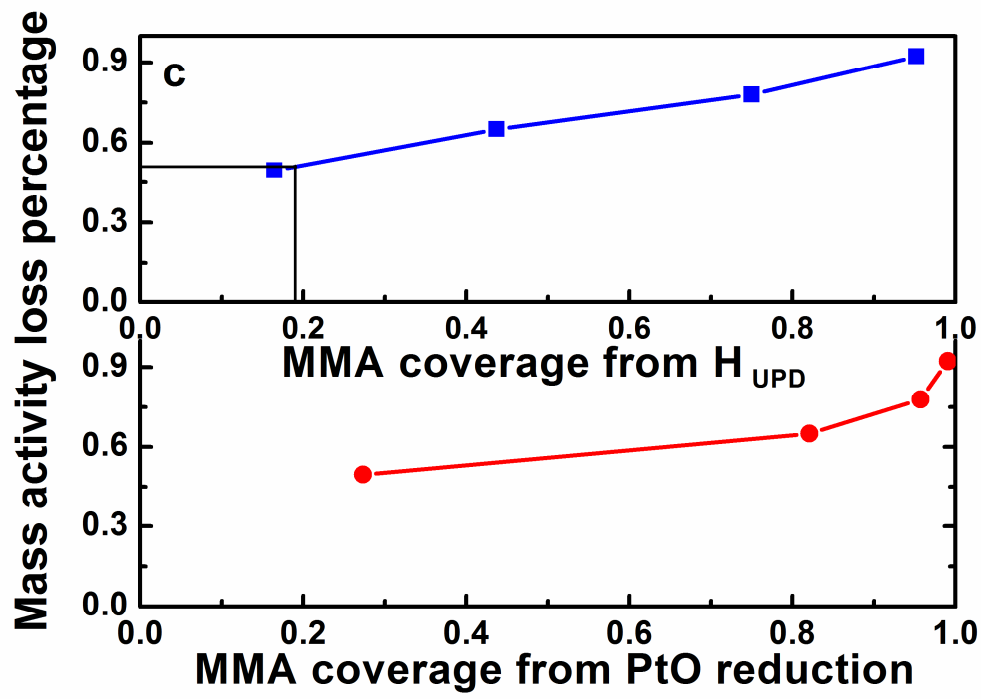

Figure 9. a) The concentration effect of the MMA on the ORR curves and the collected ring current; b) The correlation between the MMA surface coverage and the mass activity loss measured at $0.9 \mathrm{~V}$; c) The dependency of MA loss as a function of MMA coverage (obtained from $\mathrm{H}_{\mathrm{UPD}}$ and $\mathrm{PtO} / \mathrm{OH}$ reduction) on the electrode. 

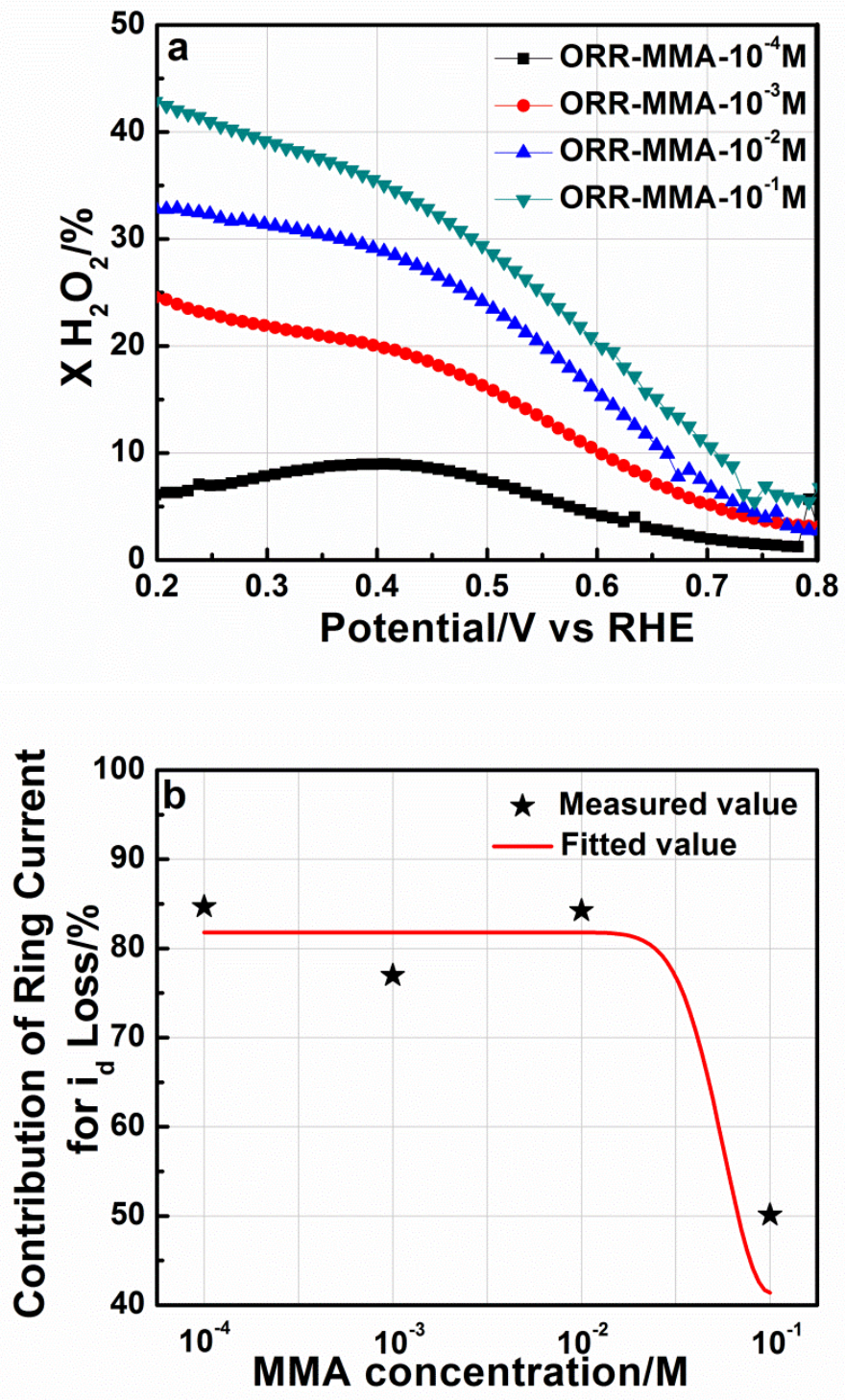

Figure 10. a) The concentration effect of the MMA on the ORR $\mathrm{H}_{2} \mathrm{O}_{2}$ percentage produced; b) The contribution of the ring current to the $i_{d}$ loss. The calculation is performed at $0.4 \mathrm{~V}$, and a Gaussian fit was used for the fitting. 


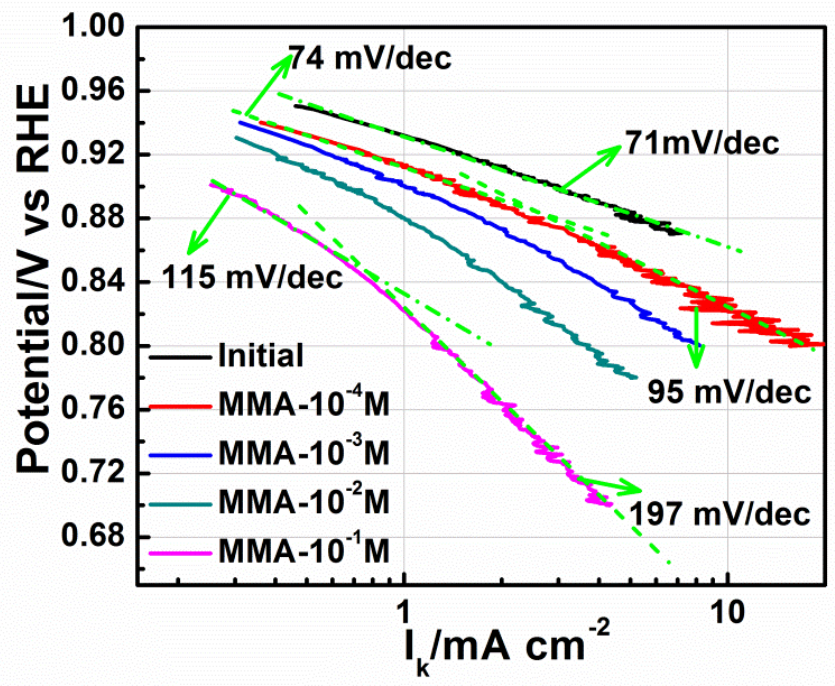

Figure 11. The Tafel plots for the ORR. 

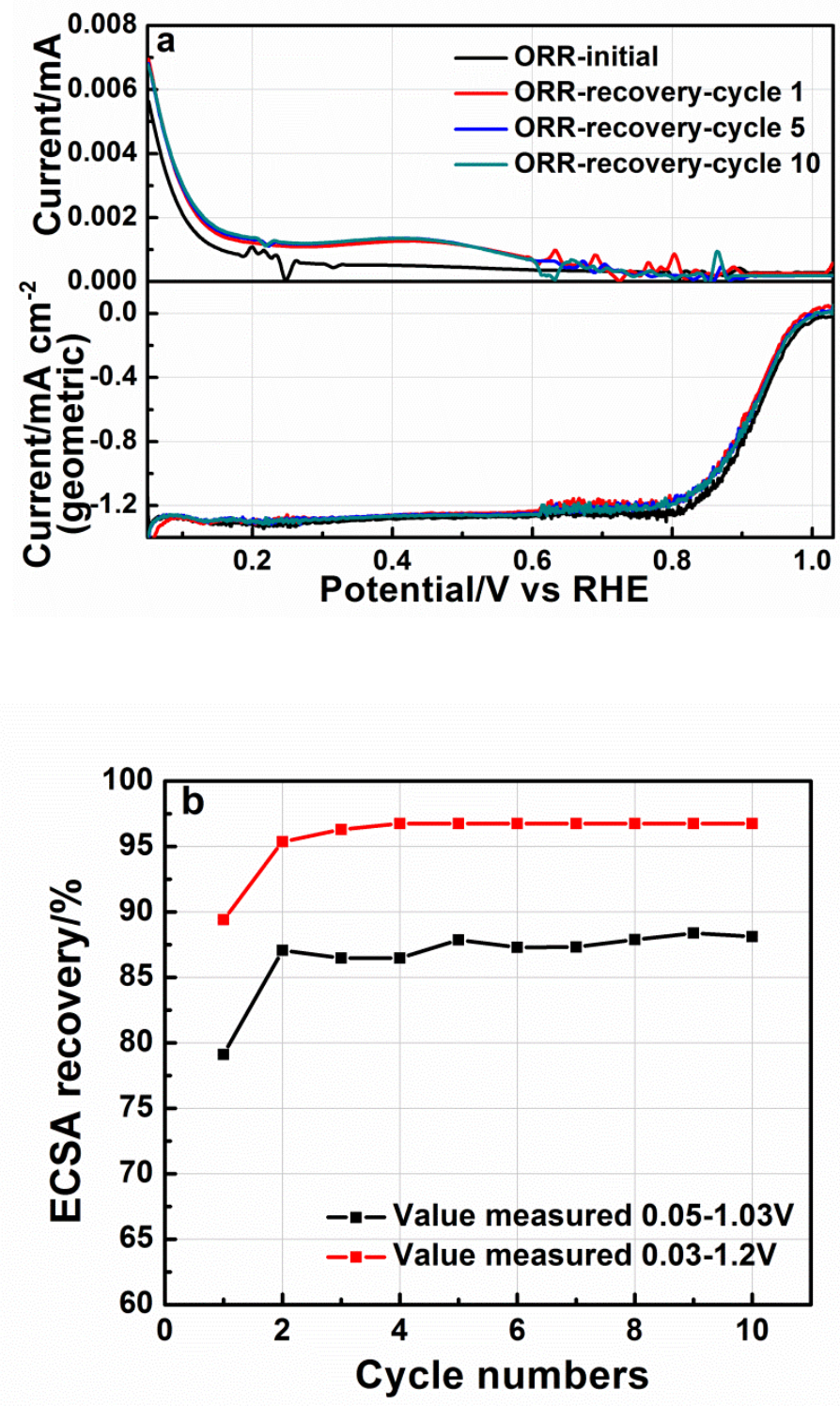

Figure 12 . The recovery effect on the electrode: a) the recovery of the ORR on the disk and the ring; b) the recovery of the ECSA at different cycles and in different potential windows. 
Scheme:

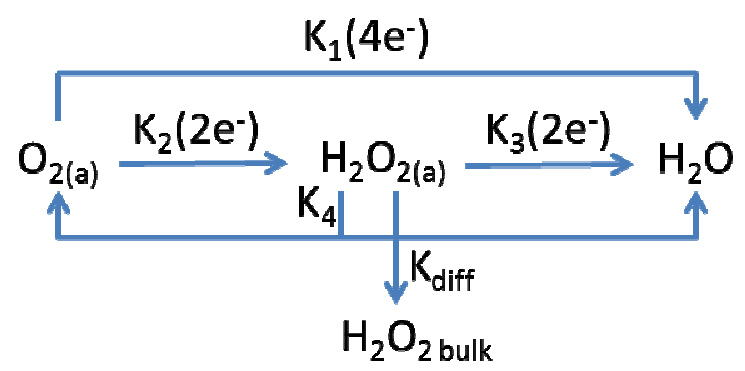

Scheme 1. Schematic illustration of the possible reactions occurring during the ORR measurements. The subscript (a) indicates the adsorbed state, bulk means the bulk solution species, and diff means the diffusion of the $\mathrm{H}_{2} \mathrm{O}_{2}$ to bulk solution. 